\title{
Histomorphometric analysis of the temporal bone after change of direction of force vector of mandible: an experimental study in rabbits
}

\author{
Edela PURICELLI ${ }^{1}$, Deise PONZONI², Jéssica Cerioli MUNARETTO ${ }^{3}$, Adriana CORSETTI ${ }^{4}$, Mauro Gomes Trein LEITE ${ }^{5}$ \\ 1- DDS, PhD, Full Professor, Service of Oral and Maxillofacial Surgery and Traumatology, Clinical Hospital of Porto Alegre; School of Dentistry, Federal \\ University of Rio Grande do Sul, Porto Alegre, RS, Brazil. \\ 2- DDS, PhD, Full Professor, Service of Oral and Maxillofacial Surgery and Traumatology, Clinical Hospital of Porto Alegre; School of Dentistry, Federal \\ University of Rio Grande do Sul, Porto Alegre, RS, Brazil. \\ 3- MSc, Dentistry Center, Santa Casa de Misericórdia of Porto Alegre - ISCMPA, Porto Alegre, RS, Brazil. \\ 4- MSc, Assistant Professor, Graduate Program in Dentistry, School of Dentistry, Federal University of Rio Grande do Sul, Porto Alegre, RS, Brazil. \\ 5- MSc, Graduate Program in Dentistry, School of Dentistry, Federal University of Rio Grande do Sul, Porto Alegre, RS, Brazil.
}

Corresponding address: - Dr. Deise Ponzoni - Faculdade de Odontologia - Universidade Federal do Rio Grande do Sul - Dario Pederneiras, 95/303 - Porto Alegre - RS - Brasil - 90630-090 - Phone: +55 5132081630 - +55 5199547538 - Fax: +55 5132226767 - e-mail: deponzoni@yahoo.com

Received: November 16, 2011 - Modification: November 28, 2011 - Accepted: December 13, 2011

\section{ABSTRACT}

Orentons bjectives: The present study aimed at performing a histological evaluation of the response of temporal bone tissue to a change of direction of the force vector of the mandible in relation to the base of the skull. Material and methods: Adult rabbits were assigned into four groups with two control and four experimental animals in each group. Experimental animals underwent surgery, which resulted in a change of direction of the force vector on the right temporomandibular joint. Samples were collected after 15, 30, 60 and 90 days for histological analysis. Results: In the two-way analysis of variance, the effect of group and time was statistically significant $(p<0.001)$. Additionally, a statistically significant interaction between group and time was observed $(p<0.001)$. Control animals showed normal growth and development of the temporal region. In the experimental group, the change in direction of the force vector of the mandible induced significant changes in the temporal bone, with a bone modeling process, which suggests growth of this cranial structure. Conclusions: The methodology used in this experiment allows us to conclude that the change in direction of the force vector of the mandible in relation to the skull base induces remodeling and modeling processes in the temporal bone. The resumption of normal oral functions after bone healing of the mandibular fracture appears to increase cell activation in the remodeling and modeling of the temporal bone structure. The observation of areas of temporal bone modeling shows the relevance of further investigation on the correlation between the joint structures and craniofacial growth and development.

Key words: Temporomandibular joint. Skull base. Facial bones. Rabbits.

\section{INTRODUCTION}

The decades of 1940 and 1950 marked the development of new studies on craniofacial growth ${ }^{9,12}$. Within this context, the temporomandibular joint (TMJ) attracted the attention of many researchers who demonstrated, in animal models mainly $y^{5,7,8,11,20}$, its high resistance to impact forces ${ }^{10}$. Different species are available, representing a large variety of anatomical models. The TMJ in New Zealand rabbits (Oryctolagus cuniculus L.) is anatomically and functionally very similar to the human $\operatorname{TMJ}^{3,6,13,18}$, which makes them one of the most widely used animals for this type of study. According to Puricelli ${ }^{14,15}(1997,2009)$, in the human TMJ the functional force vector in the mandible has a posterior-anterior/ inferior-superior direction, through the condyle towards the articular tubercle of the zygomatic process. After growth is completed, the influence of dynamic forces applied to the tissues is maintained by continuous stimulation of apposition and resorption. 
The present study aimed at evaluating the histological characteristics of temporal bone tissue submitted to a change in direction of the functional force vector of the mandible, in relation to the base of the skull, using the rabbit as an experimental model.

\section{MATERIAL AND METHODS}

Twenty-four New Zealand white rabbits aging 4 months and weighing 2.5 to $3.0 \mathrm{~kg}$ at surgery, were used in this study. All animals were treated in compliance with the Guidelines for the Care and Use of Laboratory Animals prepared by the National Academy of Sciences and published by the National Institutes of Health. This study was approved by the Ethics Committee of the School of Dentistry (Federal University of Rio Grande do Sul, Porto Alegre, RS, Brazil).

The animals were divided into four groups $(15,30,60$ and 90 days) of six rabbits, being four experimental and two control animals. After administration of antibiotics and analgesics (30 mg/ $\mathrm{kg}$ oxytetracycline and $0.03 \mathrm{mg} / \mathrm{kg}$ buprenorphine), the experimental rabbits were anesthetized with an intramuscular injection of ketamine ( $35 \mathrm{mg} / \mathrm{kg}$ ), xylazine $(5 \mathrm{mg} / \mathrm{kg}$ ) and acepromazine $(1 \mathrm{mg} / \mathrm{kg})$. A Risdon incision was used to expose the cortical bone in the region of the right mandibular angle. The rigid internal fixation system was composed of a hybrid titanium plate with four holes and microscrews (PROMM ${ }^{\circledR}$, Indústria de Materiais Cirúrgicos Ltda, Porto Alegre, RS, Brazil). Initially, a plate was positioned distal of the mandibular angle and parallel to the long axis of the mandibular body. To determine the initial positions, the plate was fixed with the aid of a curved mosquito forceps and holes were made with a No. $1 / 2$ round bur. The plate was removed and, with a No. 2 cylindrical bur, a linear osteotomy was performed on the vertical cortical bone along the axis of the mandibular body, determining the path of the fracture. The proximal mandibular segment resulting from the fracture was composed of a portion of the ascending ramus and the condyle. The plate was fixed with microscrews on the distal and then on the proximal segment (Figure 1). The new proximal position resulted in a sagittal and medial $2.8-\mathrm{mm}$ slope of the condyle, which was shifted in the anteroposterior direction. The condyle became articulate in the region of greatest convexity of the temporal bone, providing a change in the direction of the functional force vector of the mandible (Figure 2). The periosteum, muscles and skin were repositioned and sutured.

The animals received intramuscular injections of antibiotic (oxytetracycline $30 \mathrm{mg} / \mathrm{kg}$ ) twice a week, for 2 weeks. Buprenorphine was administered subcutaneously, twice daily for five days, for the relief of post-operative pain. Control animals underwent the same surgical procedure but the plate was fixed without condylar displacement in relation to the base of the skull. The segments were cut and repositioned in the same place. The rabbits were killed at postoperative days 15, 30, 60 and 90 . The specimens were removed, fixed in formalin $10 \%$ and decalcified at room temperature in $5 \%$ nitric acid, which was changed daily. After decalcification, the specimens were embedded in paraffin. Five-micrometer-thick coronal slices were stained with hematoxylin and eosin for microscopic examination. The microscopic observations and histomorphometric analysis were conducted by a previously calibrated researcher, blinded for group distribution (Kappa=0.7). For histomorphometric measurements, two microscopic fields were captured per slide at 400x magnification, using a video camera Olympus ${ }^{\circledR}$ (model QColor 5, Cooet, RTV, USA) attached to a binocular microscope Olympus Optical Co. CX41RF. A Dell ${ }^{\circledR}$ computer (model Dimension 5150), with the software Qcapture $^{\circledR}$ (version 2.81, Quantitative Imaging Corporation, Inc., USA, 2005), was used for processing the images.

To standardize the fields to be studied, an area surrounding the three joint structures (condyle, articular disc and temporal bone) was delimited. The area of the temporal bone at a new joint was measured with the software AxioVisionLE 4.6.3.011. To standardize the area of the temporal bone to be analyzed, a ruler tool of the program was used, which provided a linear measure in micrometers. The linear measurement between the posterior portion of the articular disc and the anterior portion of the mandibular condyle was used to delimitate the temporal bone, the resulting area expressed in square micrometers.

Two-way analysis of variance, with group and time as fixed factors, was used to evaluate changes in bone area. The Bonferroni test was used for

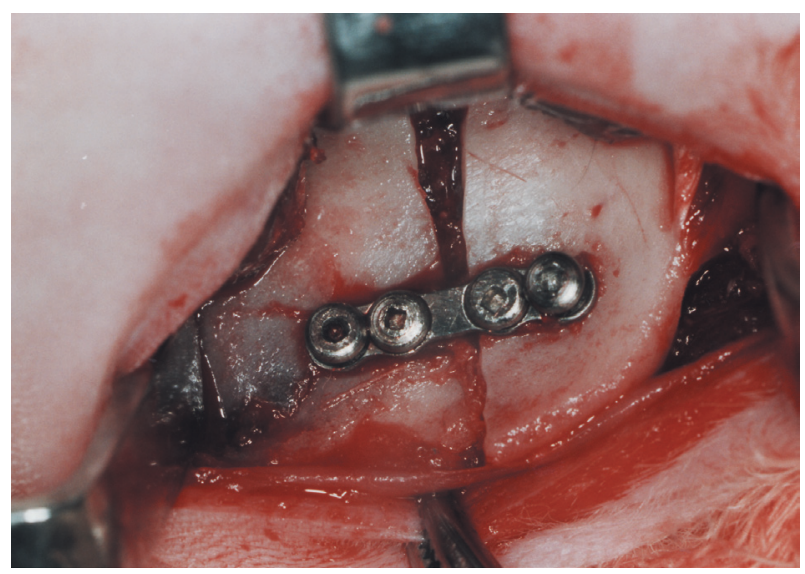

Figure 1- Fixation of bone segments with hybrid microplate and microscrews 

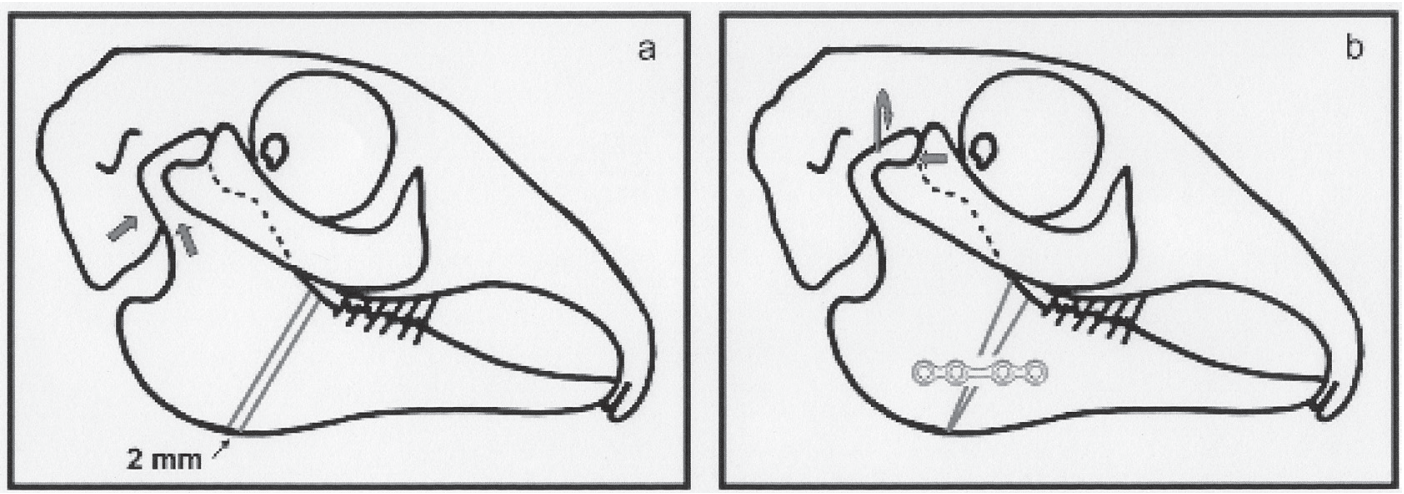

Figure 2- Schematic drawing of the skull of the rabbit: a) preoperative, b) after changing the direction of the force vector of the mandible in relation to the base of the skull

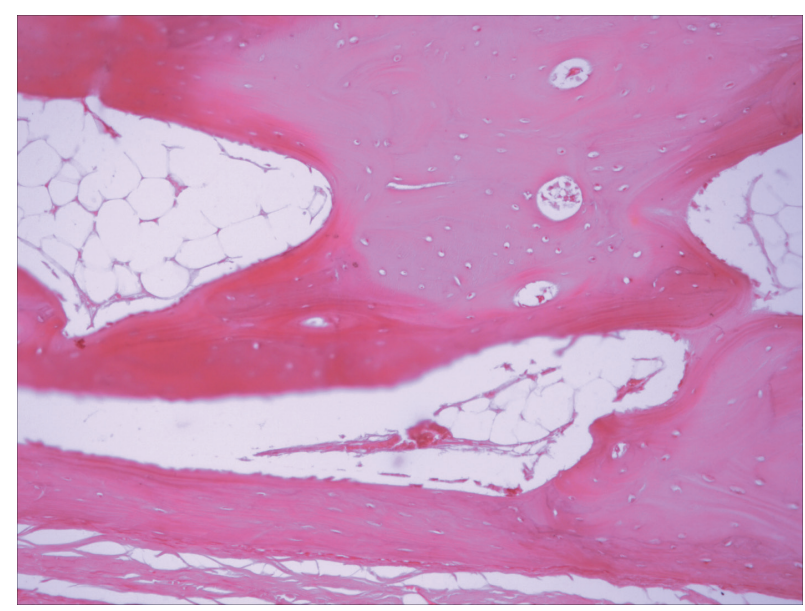

Figure 3- Temporomandibular joint (TMJ) area in an experimental sample, day 90 . Bone layers are irregular, showing appositional growth compatible with bone modeling $(\rightarrow)$ Original magnification 250x, hematoxylin \& $\operatorname{eosin}(\mathrm{HE})$

multiple comparisons over time. Statistical analyses were performed using SPSS version 16 or Macintosh (SPSS Inc., Chicago, IL, USA). The rabbit was considered the unit of analysis, and the significance level was set at $5 \%$.

\section{RESULTS}

No infections or wound dehiscence were observed during the experimental period in the different groups. Intense cartilage activity was observed in the temporal bone in experimental samples collected on day 15 , with the presence of chondrocytes and islets of hyaline cartilage in the deeper layers of the fibrocartilage lining. Similar results were observed on day 30 samples and were more marked after 60 days, with greater cartilage cell activity. In control samples, on the other hand, the fibrocartilaginous lining remained thin, with a uniform thickness, when compared to experimental samples in the same periods. Intense activity was also observed in temporal bone samples from

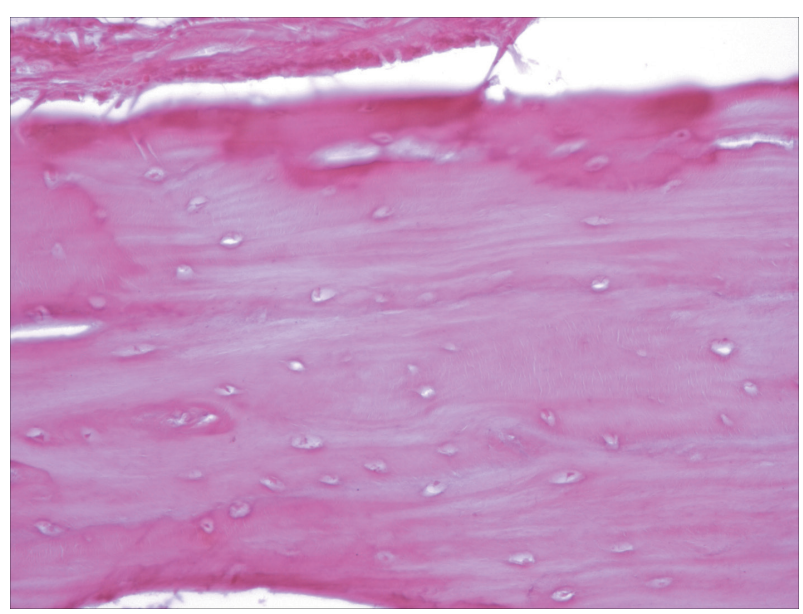

Figure 4- Non-articulated area of the temporal bone, control sample, day 90. Bone layers show appositional growth, typical of remodeling $(\rightarrow)$. Original magnification 400x, hematoxylin \& eosin (HE)

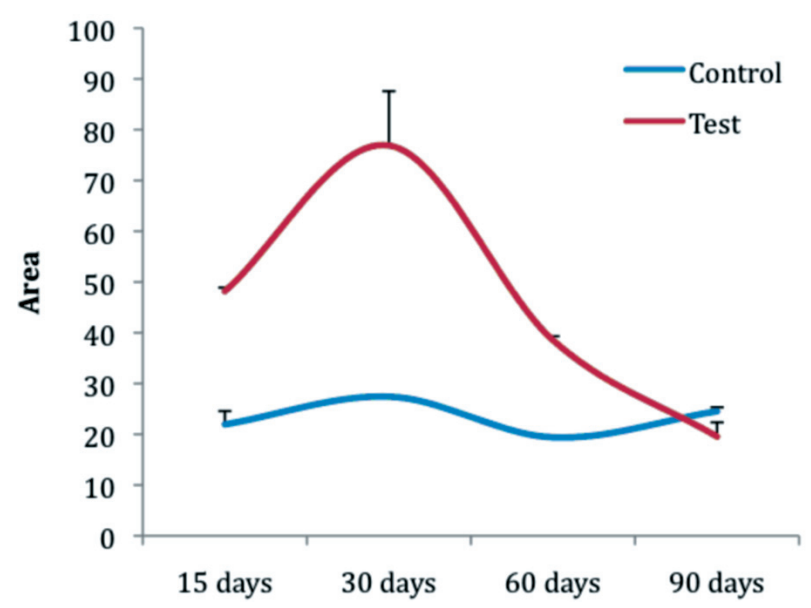

Figure 5- Mean bone area $\left(\mathrm{mm}^{2}\right)$ in test and control groups (bars indicate standard errors)

experimental animals on day 15 , with the presence of an osteoid tissue.

At 30 days, areas of bone remodeling with characteristics of reorganization were observed, with a decrease in marrow spaces. At 60 days, bone 
modeling and remodeling characterized a mature bone tissue surrounding vascular channels. At 90 days, experimental samples showed irregular bone layers, which indicated a convoluted appositional growth, consistent with areas of bone modeling (Figure 3). Histological analyses of the temporal bone in the control group along different periods showed that growth and development of this structure was in accordance to normal patterns (Figure 4). Means and standard errors for bone area were calculated and reported for each experimental group and day.

In the two-way analysis of variance, the effect of group and time was statistically significant $(p<0.001)$. Additionally, the interaction between group and time was found to be statistically significant $(p<0.001)$ (Figure 5$)$.

\section{DISCUSSION}

Our results showed that the change in direction of the functional force vector of the mandible affected areas which are not usually subject to dynamic forces, inducing adjustments in these regions. Under these new circumstances, changed forces probably affected areas of the temporal bone that are not required under normal conditions. Possibly, the change in direction of the force vector caused by the condyle displacement exceeded the disc capacity to absorb it and dissipate it, inducing the modification observed in the temporal bone ${ }^{19}$.

The present results, obtained in adult animals, reinforce the hypothesis that the potential of articular surfaces in TMJ to adapt persists into adulthood and can respond to stimuli arising from changes in joint biomechanics ${ }^{4}$. We agree with the hypothesis that the histological composition of the articular surface of the temporal bone is determined by the different characteristics of mechanical forces that affect the region during movement ${ }^{4,16}$. The modeling of the temporal bone at 90 days could be associated with the fact that chondrogenic responses are induced in regions where dynamic forces are higher, whereas osteogenic responses are seen where they are reduced as already previously described ${ }^{17}$. Comparison of experimental and control groups showed that histological changes are more related to functional stimulation than to age $^{16}$. Chondrogenesis is increased with increased functional stimulation ${ }^{17,18}$.

Our results suggest that the adaptive response of the TMJ to modifications in the direction of force vector of the mandible were directly related to the intensity, duration, frequency and direction of the mechanical forces and to the adaptive capacity of the TMJ. This study shows a correlation between the increase of cartilage thickness and a decrease in the number of cartilaginous cells in response to increased forces on the surface of the temporal bone as already previously described ${ }^{8}$. The experimental results of this study agree with the observations of Puricelli14,15 $(1997,2009)$, who reported growth of the skull base as a possible functional compensation to a change in direction of the force vector of the mandible over the TMJ. Haversian systems describe a secondary, more differentiated bone, which involves a remodeling process ${ }^{2}$. Remodeling reorganizes the various parts of the bone as it increases in size. The changes induced by remodeling are mediated by various combinations of deposition and resorption processes on the endosteal and periosteal surfaces. Haversian remodeling is a process of reconstruction within the cortex, with no modifications on the internal and external surfaces ${ }^{2}$. In the present study, this process was markedly present in the temporal bone of experimental animals on day 90 .

\section{CONCLUSIONS}

The methodology used in this experiment allows us to conclude that the change in direction of the force vector of the mandible in relation to the skull base induces remodeling and modeling processes in the temporal bone. The resumption of normal oral functions after bone healing of the mandibular fracture appears to increase cell activation in the remodeling and modeling of the temporal bone structure. The observation of areas of temporal bone modeling shows the relevance of further investigation on the correlation between the joint structures and craniofacial growth and development.

\section{ACKNOWLEDGEMENTS}

The authors kindly appreciate the help of the dental surgeon Viviane Neves Pacheco and of the Dentistry student Alessandra Cláudia Junges.

\section{REFERENCES}

1- Di Iorio E, Barbaro V, Ferrari S, Ortolani C, De Luca M, Pellegrini G. Q-FIHC: quantification of fluorescence immunohistochemistry to analyse p63 isoforms and cell cycle phases in human limbal stem cells. Microsc Res Tech. 2006;69:983-91.

2- Enlow DH. Facial growth and development. Int J Oral Myol. 1979;5:7-10.

3- Fujimura K, Kobayashi S, Suzuki T, Segami N. Histologic evaluation of temporomandibular arthritis induced by mild mechanical loading in rabbits. J Oral Pathol Med. 2005;34:157-63. 4- Hinton RJ. Changes in articular eminence morphology with dental function. Am J Phys Anthropol. 1981;54:439-55.

5- Karaharju-Suvanto T, Peltonen J, Laitinen O, Kahri A. The effect of gradual distraction of the mandible on the sheep temporomandibular joint. Int J Oral Maxillofac Surg. 1996;25:1526.

6- Lai WF, Tsai YH, Su SJ, Su CY, Stockstill JW, Burch JG. Histological analysis of regeneration of temporomandibular joint discs in rabbits by using a reconstituted collagen template. Int J Oral Maxillofac Surg. 2005;34:311-20. 
7- Li Z, Zhang W, Li ZB. The role of the disc in the healing of displaced subcondylar fracture in the growing period: an experimental study in rats. Int J Oral Maxillofac Surg. 2010;39:388-93.

8- McCormick SU, McCarthy JG, Grayson BH, Staffenberg D, McCormick SA. Effect of mandibular distraction on the temporomandibular joint: part 1, Canine study. J Craniofac Surg. 1995;6:358-63.

9- Mongini F. Remodelling of the mandibular condyle in the adult and its relationship to the condition of the dental arches. Acta Anat (Basel). 1972;82:437-53.

10- Mongini F, Tempia-Valenta G, Conserva E. Habitual mastication in dysfunction: a computer-based analysis. J Prosthet Dent. 1989;61:484-94.

11- Monje F, Delgado E, Navarro MJ, Miralles C, Alonso del Hoyo JR. Changes in temporomandibular joint after mandibular subcondylar osteotomy: an experimental study in rats. J Oral Maxillofac Surg. 1993;51:1221-34.

12- Moyers RE. An electromyographic analysis of certain muscles involved in temporomandibular movement. Am J Orthod. $1950 ; 36: 481-515$.

13- Nagy NB, Daniel JC. Development of the rabbit craniomandibular joint in association with tooth eruption. Arch Oral Biol. 1992;37:271-80.
14- Puricelli E. Artroplastia biconvexa para tratamento da anquilose da articulação temporomandibular. Rev Fac Odontol Porto Alegre. 1997;38:23-7.

15- Puricelli E. Cirugía bucomaxilofacial en el paciente pediatrico. In: Villa CN, Marín FG, Caicoya SO. Tratado de cirugía oral y maxilofacial. Madrid: Arán; 2009. p. 1879-901.

16- Richards LC, Lau E, Wilson DF. Histopathology of the mandibular condyle. J Oral Pathol. 1985;14:624-30.

17- Silbermann M, Lewinson D, Gonen $H$, Lizarbe MA, von der Mark K. In vitro transformation of chondroprogenitor cells into osteoblasts and the formation of new membrane bone. Anat Rec. 1983;206:373-83.

18- Tallents RH, Macher DJ, Rivoli P, Puzas JE, Scapino RP, Katzberg RW. Animal model for disk displacement. J Craniomandib Disord. $1990 ; 4: 233-40$.

19- Tuominen M, Kantomaa T, Pirttiniemi P. Effect of food consistency on the shape of the articular eminence and the mandible. An experimental study on the rabbit. Acta Odontol Scand. 1993;51:65-72.

20- Yamaki Y, Tsuchikawa K, Nagasawa T, Hiroyasu K. Embryological study of the development of the rat temporomandibular joint: highlighting the development of the glenoid fossa. Odontology. 2005;93:30-4. 